\title{
MONETARY POLICY IN A CREDIT-IN-ADVANCE ECONOMY
}

Emanuel Leão

Outubro 2001

WP $\mathrm{n}-2001 / 20$

DOCUMENTO DE TRABALHO

WORKI NG PAPER 
Emanuel Leão is Auxiliary Professor at the Departament of Economics of the Instituto Superior de Ciências do Trabalho e da Empresa (ISCTE) and Research Fellow of the Dinâmia (Centro de Estudos sobre a Mudança Socioeconómica).

The author has received helpful comments from Alan J. Sutherland, Peter N. Smith, Michael R. Wickens, Morten O. Ravn, John P. Hutton and participants at the Young Economists Conference Oxford 2000. They are in no way responsible for the interpretations or any errors that the paper may contain. 


\title{
MONETARY POLICY IN A CREDIT-IN-ADVANCE ECONOMY
}

\author{
Emanuel Reis Leão \\ E-mail: eccl@iscte.pt
}

\section{Index}

Abstract 2

List of Symbols 3

1. Introduction 5

2. The Economic Environment 6

3. The Typical Bank's Behaviour 8

4. The Typical Firm's Behaviour 9

5. The typical Household's Behaviour $\quad 10$

$\begin{array}{ll}\text { 6. The Market Clearing Conditions } & 14\end{array}$

7. The Competitive General Market Equilibrium assuming $\mathrm{H}$ homogeneous households, $\mathrm{F}$ homogeneous firms and $\mathrm{L}$ homogeneous banks plus Rational Expectations 15

8. Calibration 20

9. The Dynamic Properties of the Model 22

9.1. The impact of technological shocks 22

9.2. Monetary Policy 24

10. Conclusion 26

$\begin{array}{ll}\text { Appendix } & 27\end{array}$

$\begin{array}{ll}\text { References } & 31\end{array}$

$\begin{array}{ll}\text { Tables } & 32\end{array}$

$\begin{array}{ll}\text { Figures } & 34\end{array}$ 


\section{$\underline{\text { Abstract }}$}

In the benchmark dynamic general equilibrium model with money [Cooley and Hansen (1989)], money is supplied to the economy in a way which may be argued to be not very realistic. In this paper, we develop a dynamic general equilibrium model where bank loans are the source of money creation. We show that the same results follow as in Cooley and Hansen. In particular, monetary policy has only very small real effects in the model.

Keywords: Dynamic General Equilibrium Models, Cash-in-Advance, Monetary Policy.

JEL Classification: E17, E41, E52 (The full list of JEL codes can be found at http://www.aeaweb.org/journal/elclasjn.html) 


\section{List of Symbols}

$c_{t}$
$\ell_{t}$
$n_{t}^{s}$
$B_{t+1} /\left(1+R_{t}\right)$
$B_{t+1}$
$z_{t}^{f}$
$z_{t}^{\text {bank,l}}$

\section{HOUSEHOLD VARIABLES}

household's consumption in real terms

leisure

household's supply of labour

the amount the household borrows at the beginning of period $t$

household's debt at the beginning of period $(\mathrm{t}+1)$

$\%$ of firm $\mathrm{f}$ that the household buys at beginning of period ( $\mathrm{t}-1)$

and sells at beginning of period $t$

$\%$ of bank 1 that the household buys at beginning of period ( $\mathrm{t}-1$ )

and sells at beginning of period $t$

$C D_{t}$

amount of checkable deposits the household decides

to hold at the beginning of period $t$

$\lambda_{t}$

$\beta$

shadow price (marginal utility of consumption, in this model)

intertemporal discount factor

\section{FIRM VARIABLES}

$y_{t} \quad$ firm's output

$k_{t} \quad$ firm's stock of capital

$n_{t}^{d} \quad$ firm's labour demand

$i_{t} \quad$ firm's investment

$\Pi_{t}^{f} \quad$ nominal profits of firm $\mathrm{f}$ in period $\mathrm{t}$

$\delta \quad$ per period rate of depreciation of the firm's capital stock

\section{BANK VARIABLES}

$B_{t}^{s}$

bank's nominal supply of credit at the beginning of period $t$

bank's reserves in period t

$r^{r e q}$

nominal profits of bank 1 in period $t$

required reserve ratio

PRICE VARIABLES

$P_{t} \quad$ price of physical output

$W_{t} \quad$ nominal wage rate

$R_{t} \quad$ nominal interest rate between the beginning of period $t$ and the beginning of period $(t+1)$

$Q_{t}^{f} \quad$ nominal price of firm $\mathrm{f}$ at beginning of period $\mathrm{t}$ (amount necessary to buy $100 \%$ of firm $\mathrm{f}$ )

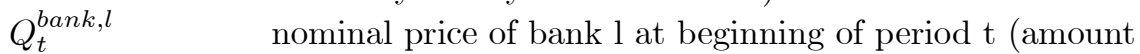
necessary to buy $100 \%$ of bank l)

\section{SHOCK VARIABLES}

$A_{t}$

firm's technological parameter

$\mu_{t}$

rate of growth of the level of reserves between the beginning of period ( $\mathrm{t}-1$ ) and the beginning of period $\mathrm{t}$ 


$$
\begin{aligned}
& x \quad \text { steady-state value of variable } x_{t} \\
& \widehat{x_{t}} \text { the percentage deviation of variable } x_{t} \text { from its steady-state (in period t) } \\
& E_{t}[.] \quad \text { expectation conditional on information pertaining to the beginning } \\
& \text { of period } t \text { and earlier of the indicated argument } \\
& \mathrm{H} \quad \text { number of households } \\
& \mathrm{F} \quad \text { number of firms } \\
& \text { L number of banks } \\
& b_{t+1}=\frac{B_{t+1}}{R E S_{t-1}} \\
& b_{t}^{s}=\frac{B_{t}^{s}}{R E S_{t-1}} \\
& p_{t}=\frac{P_{t}}{R E S_{t-1}} \\
& w_{t}=\frac{W_{t}}{R E S_{t-1}} \\
& q_{t}^{f}=\frac{Q_{t}^{f}}{R E S_{t-1}} \\
& q_{t}^{b a n k, l}=\frac{Q_{t}^{b a n k, l}}{R E S_{t-1}} \\
& \pi_{t}^{f}=\frac{\Pi_{t}^{f}}{R E S_{t-1}} \\
& \pi_{t}^{b a n k, l}=\frac{\Pi_{t}^{\text {bank }, l}}{R E S_{t-1}} \\
& \bar{k}_{t}=\frac{F}{H} k_{t} \\
& \bar{n}_{t}^{d}=\frac{F}{H} n_{t}^{d} \\
& \bar{q}_{t}^{f}=\frac{F}{H} q_{t}^{f} \\
& \bar{q}_{t}^{b a n k, l}=\frac{L}{H} q_{t}^{b a n k, l} \\
& \bar{\pi}_{t}^{f}=\frac{F}{H} \pi_{t}^{f} \\
& \bar{\pi}_{t}^{b a n k, l}=\frac{L}{H} \pi_{t}^{b a n k, l}
\end{aligned}
$$




\section{Introduction}

Cooley and Hansen (1989) add money to the dynamic general equilibrium model of Hansen (1985). The way money is fed into the economy in the model of Cooley and Hansen can be summarized as follows. Households start every period with a given amount of money carried over from the previous period and they then receive a lump-sum transfer from the government (which, supposedly, has obtained it from the central bank). This mechanism of injecting money into the economy stands in sharp contrast with the fact that, in modern economies, most money has its origin in loans from commercial banks to households, firms or the government.

In this paper, we add money to a zero growth version of the dynamic general equilibrium model presented in King, Plosser and Rebelo (1988). In the model we build, all money has its origin in loans that the households obtain from commercial banks.

In our model there are only households, nonbank firms, commercial banks and a central bank (in this paper, we shall refer to "nonbank firms" simply as "firms"; likewise, we shall refer to "commercial banks" simply as "banks"). Banks make loans to households at the beginning of each period and households then use the money obtained in this way to buy consumption goods from the firms.

We have log-linearized the competitive equilibrium around the steady-state values of its variables and then calibrated it using Postwar data. Afterwards, we examined the response of the model to technological shocks and to monetary policy shocks.

Our simulation experiments gave us the same pattern of results that was obtained by Cooley and Hansen: ( $\mathrm{i}$ ) when money is supplied to the economy at a constant rate of growth, the behaviour of the real variables in the presence of technological shocks is the same that is obtained using the same model without money; ( ii ) when money is supplied to the economy at a constant rate of growth, the actual rate of growth at which it is supplied has no influence on the results we obtain when the model is hit by technological innovations; ( iii ) when there are shocks to the rate of growth of the money supply, the behaviour of the real variables changes only slightly and most of the impact goes to the price level.

The structure of the article is as follows. In section 2, we describe the economic environment: preferences, technology, resource constraints and market structure. In section 3, we describe the typical bank's behaviour. In section 4, we describe the typical firm's behaviour. In section 5, we describe the typical household's behaviour. In section 6 , we write down the market clearing conditions. In section 7 , we write the set of equations that describes the competitive general market equilibrium. In section 8 , we describe the calibration of the model. In section 9 , we look at the response of the model to technological shocks and to monetary policy shocks. In section 10, we make an overview and conclusion. 


\section{The Economic Environment}

This is a closed economy model with no government. There are $\mathrm{H}$ homogeneous households, $\mathrm{F}$ homogeneous firms, L homogeneous banks and a central bank. Firms and banks are owned by the households. As a consequence, both the firms' profits and the banks' profits are distributed to households (the shareholders) at the end of each period.

There is only one (homogeneous) physical good produced in this economy which we denote physical output. There are two possible uses for this output: it can either be consumed or used for investment (i.e., used to increase the level of the stock of capital).

In our model, the only source of money is loans from commercial banks to households. At the beginning of each period, commercial banks obtain reserves from the central bank which allow them to make loans to households. In making loans to households, at the beginning of each period, commercial banks create deposits which did not exist before. Households pay the amount borrowed at the end of the same period thereby destroying the deposits which had been created at the beginning of the period.

Let us now concentrate on the way the household's demand for credit is modelled.

When we start thinking about modelling household borrowing, a key issue that we have to deal with is the household's initial debt position. If period 0 is the period where our analysis of the economy is starting (the present date, for example) and the household has been living for some periods before arriving at the beginning of period 0 , what debt should we assume that she carries from the previous period? In this article, we propose using a specific initial condition to describe the household's initial debt position. In the Appendix we show that the initial condition we use is the initial condition which naturally arises when we think the economy back to its initial moment. In any case, other initial conditions can and should be tried. What we cannot do is avoid modelling the initial debt position of the household.

The initial condition on the typical household's optimization problem that we use is: at the beginning of the period where our analysis of the economy is starting (period 0), the typical household owes the banks an amount which equals the sum of the wage earnings and dividend earnings that she received at the end of the previous period. After paying the debt to the banks, the household is left with nothing (the household also owns shares but, because households are all alike, shares are not traded in equilibrium) and must therefore borrow again from the banks to finance her consumption expenditure during the period that is just beginning (period 0). The market clearing conditions of the model together with the definitions of profits imply that the amount the household borrows at the beginning of period 0 is such that when she arrives at the end of period 0 she will again be left with nothing (after paying the debt to the banks). The consequence is that the household will need to borrow again from the banks at the beginning of period 1 in order to finance her consumption expenditure during this period. And this story is repeated every period into the future. All this is achieved by the introduction of the initial condition that we have just mentioned. 
The complete description of monetary flows among economic agents is as follows. At the beginning of each period, the typical household borrows from the banks the amount that she needs in order to be able to buy consumption goods from the firms during the period that is beginning. Loans obtained from a bank take the form of checkable deposits. During the period, the typical household spends these checkable deposits buying consumption goods from the firms. At the end of the period, the household receives back from the firms these checkable deposits (as wage payments and dividend payments). Then, the household pays the banks interest on the amount borrowed at the beginning of the period (the amount of interest due is paid by reducing the amount of checkable deposits that the household owns at the banks). However, since banks are owned by the households and households are all alike, the household immediately receives back the amount of interest paid to the banks (in the form of bank dividends). Afterwards, the household pays the banks the principal of the debt contracted at the beginning of the period. The structure of the model is such that, after all these payments, the household is left with nothing and must therefore borrow again from the banks at the start of the new period.

Since all transactions in our economy are financed by bank loans, it can be labelled a pure credit economy (as defined by Wicksell).

It is important to emphasize that the precise credit structure of the model depends on the initial condition we choose. It is the initial condition that transforms a cash-in-advance economy into a specific credit-in-advance economy.

We next examine the typical household's preferences, the technology available in the economy (production function and capital accumulation equation), the resource constraints that exist in a given period and the market structure.

Let us suppose that we are at the beginning of period 0 and that households, firms and banks are considering decisions for periods $t$ with $t=0,1,2,3, \ldots$.

Let us start by describing the preferences of the typical household. The typical household seeks to maximize lifetime utility. Utility in period $t$ is given by $u\left(c_{t}, \ell_{t}\right)$ where $c_{t}$ is the flow amount of consumption and $\ell_{t}$ is the amount of leisure enjoyed in that period. The function $u(.,$.$) has the usual$ properties. At the beginning of period 0 , the household maximizes $U_{0}=E_{0}\left[\sum_{t=0}^{t=\infty} \beta^{t} u\left(c_{t}, \ell_{t}\right)\right]$ where $\beta$ is a discount factor $(0<\beta<1)$ that reflects a preference for current over future consumptionleisure bundles. Application of the operator $E_{0}[$.$] yields the mathematical expectation, conditional$ on complete information pertaining to the beginning of period 0 and earlier, of the indicated argument.

Let us now describe the technology available in the economy: production function and capital accumulation equation. Each firm's production function is described by $y_{t}=A_{t} F\left(k_{t}, n_{t}^{d}\right)$ where $y_{t}$ is the physical output of the firm, $A_{t}$ is a technological parameter, $k_{t}$ is the firm's stock of capital and $n_{t}^{d}$ is the firm's labour demand in period $t$. Capital accumulation is described by $k_{t+1}=(1-\delta) k_{t}+i_{t}$ where $i_{t}$ is the flow of investment in period $t$ and $\delta$ is the per-period rate of depreciation of the stock of capital which is assumed to be constant and belonging to the closed interval $[0,1]$. 
The resource constraints are as follows. Each firm starts period $t$ with a stock of capital $k_{t}$ which is pre-determined [which was determined at the beginning of period $(t-1)$ ]. In other words, the stock of capital that will enter the production function in period $t$ cannot be changed by decisions taken during period $t$. Each household has an endowment of time per-period which is normalized to be equal to one by an appropriate choice of units. This amount of time can be used to work or to rest. Therefore, we can write $n_{t}^{s}+\ell_{t}=1$ where $n_{t}^{s}$ is the household's supply of labour during period $t$.

There is a legal constraint which implies that the total amount of credit that each commercial bank can offer cannot exceed a certain amount. This may be seen as a restriction set by the existence of a required reserve ratio together with a fixed amount of reserves made available to each bank. Therefore, the maximum amount of credit that each bank can lend is denoted by $\frac{1}{r^{r e q}} R E S_{t}$ where $R E S_{t}$ is the total reserve endowment of each bank and $r^{r e q}$ is the required reserve ratio. In this model, reserves pay no interest.

Let us now describe the market structure. There are five markets: the goods market, the labour market, the bank loans' market, the market for firms' shares and the market for banks' shares. We assume that each household behaves as a price-taker, each firm behaves as a price-taker and each bank also behaves as a price-taker. Prices are perfectly flexible and adjust so as to clear all markets in every period.

\section{The Typical Bank's Behaviour}

In this model, each commercial bank receives an endowment of reserves from the central bank at the beginning of period $t$ which is denoted $R E S_{t}$. We assume that the commercial bank pays no interest to the central bank because of this amount of reserves it receives. It is also assumed that commercial banks have no costs of operation. On the other hand, commercial banks operate under a fractional reserve system (with the required reserve ratio denoted $r^{r e q}$ ). The combination of a fixed amount of reserves made available to each bank with a required reserve ratio means that there is an upper bound on the amount of credit that the bank can supply in each period. Alternatively, we can think of this upper bound on the amount of credit that each bank can supply as resulting from some capital requirement ratio such as the Basle Capital Accord, also known as Cook Ratio. In the model, we shall reason as if the upper bound on the banks ability to supply credit were the result of a required reserve ratio. The alternative motivation of this upper bound as resulting from a capital requirement ratio has been mentioned because it may be more appealing for economists living in countries where there is no required reserve ratio or where this ratio is very low.

With the present assumptions (no costs of obtaining reserves and no costs of operation), as long as the lending rate is always strictly positive, banks will always want to supply the maximum amount of credit that they can. Therefore, the supply of credit by each bank in period $t$ is just the fixed amount $\frac{1}{r^{r e q}} R E S_{t}$. To see this mathematically, we first note that, under the present assumptions, the profits of bank 1 in period $t$ are given by $\Pi_{t}^{b a n k, l}=R_{t} B_{t}^{s}$ where $R_{t}$ is the nominal 
interest rate (lending rate) between the beginning of period $t$ and the beginning of period $(t+1)$ and $B_{t}^{s}$ is the nominal amount of credit supplied by the bank. The profits earned by each bank during period $t$ are distributed to households at the end of the period in the form of dividends.

Each bank maximizes the Value of its Assets (VA), i.e., the expected discounted value of its stream of present and future dividends. Therefore, when we are at the beginning of period 0 , the typical bank's optimization problem is

$$
\begin{aligned}
& \underset{B_{t}^{s}}{\operatorname{Max} V A=} E_{0}\left[\sum_{t=0}^{t=\infty} \frac{1}{1+R_{0, t+1}} R_{t} B_{t}^{s}\right] \\
& \text { s.t. } \quad B_{t}^{s} \leq \frac{1}{r^{r e q}} R E S_{t} \quad \text { for } \mathrm{t}=0,1,2,3, \ldots
\end{aligned}
$$

Given the economic environment we are working with, we think it is appropriate to assume that

$$
\begin{gathered}
\left(1+R_{0, t+1}\right)=\left(1+R_{0}\right)\left(1+R_{1}\right)\left(1+R_{2}\right) \ldots\left(1+R_{t}\right) \\
\text { for } t=0,1,2, \ldots
\end{gathered}
$$

Note that we are at the beginning of period 0 . Therefore, because dividends are only distributed at the end of the period, we discount period 0 dividends by multiplying them by $1 /\left(1+R_{0}\right)$, we discount period 1 dividends by multiplying them by $1 /\left[\left(1+R_{0}\right)\left(1+R_{1}\right)\right], \ldots$

As long as the nominal interest rate is always strictly positive, the solution to the bank's optimization problem will obviously be

$$
\begin{aligned}
& B_{t}^{s}=\frac{1}{r^{r e q}} R E S_{t} \\
& \quad \text { for } t=0,1,2, \ldots
\end{aligned}
$$

We assume that the endowment of reserves grows over time [the rate of growth of the level of reserves between the beginning of period (t-1) and the beginning of period $t$ is denoted $\left.\mu_{t}\right]$. Hence, $B_{t}^{s}$ will also grow over time.

Note that the nominal profits of bank 1 in period $t$ can be written as

$$
\Pi_{t}^{\text {bank }, l}=\frac{1}{r^{r e q}} R E S_{t} R_{t}
$$

\section{The Typical Firm's Behaviour}

The focus of the article is on modelling the demand for bank credit by households and the supply of credit by commercial banks. Hence, the behaviour of firms is modelled in a standard way. In nominal terms, the profits of firm $\mathrm{f}$ in period $t$ are given by income from the sale of output minus the wage bill minus investment expenditure

$$
\Pi_{t}^{f}=P_{t} A_{t} F\left(k_{t}, n_{t}^{d}\right)-W_{t} n_{t}^{d}-P_{t}\left[k_{t+1}-(1-\delta) k_{t}\right]
$$

where $P_{t}$ is the nominal price of goods in period $t$ and $W_{t}$ is the nominal wage in period $t$. The firm pays wages to households at the end of the period. The profits earned by each firm during 
period $t$ are distributed to households at the end of the period in the form of dividends. Each firm $\mathrm{f}(f=1,2, \ldots, F)$ maximizes the Value of its Assets (VA), i.e., the expected discounted value of the stream of present and future dividends. Therefore, when we are at the beginning of period 0 , the typical firm's optimization problem is

$$
\underset{n_{t}^{d}, k_{t+1}}{\operatorname{Max}} V A=E_{0}\left[\sum_{t=0}^{t=\infty} \frac{1}{1+R_{0, t+1}} \Pi_{t}^{f}\right]
$$

where

$$
\Pi_{t}^{f}=P_{t} A_{t} F\left(k_{t}, n_{t}^{d}\right)-W_{t} n_{t}^{d}-P_{t}\left[k_{t+1}-(1-\delta) k_{t}\right]
$$

for $\mathrm{t}=0,1,2, \ldots$

There is also an initial condition for the capital stock, the standard transversality condition for the capital stock and non-negativity constraints.

\section{The Typical Household's Behaviour}

In this section we present the typical household's problem written in a cash-in-advance form which was learned from Lucas (1982), i.e., using a portfolio allocation constraint and a cash-in-advance constraint.

The way loans work in this model is as follows. We have mentioned that $R_{t}$ denotes the nominal interest rate between the beginning of period $t$ and the beginning of period $(t+1)$. At the beginning of period $\mathrm{t}$, the household borrows from banks the amount $\frac{B_{t+1}}{1+R_{t}}$. This means that the household receives $\frac{B_{t+1}}{1+R_{t}}$ monetary units at the beginning period $t$ and that she will have to pay $\frac{B_{t+1}}{1+R_{t}}\left(1+R_{t}\right)=B_{t+1}$ monetary units at the end of period $\mathrm{t}$ [beginning of period $(t+1)$ ]. Hence, $B_{t+1}$ denotes the debt the household has at the beginning of period $(t+1)$.

The way shares work in this model is as follows. $Q_{t}^{f}$ is the nominal price that the household would have to pay to buy $100 \%$ of firm $\mathrm{f}$ at the beginning of period $\mathrm{t} . z_{t}^{f}$ is the percentage of firm $\mathrm{f}$ [i.e. the share of firm $\mathrm{f}$ ] that the household bought at the beginning of period $(\mathrm{t}-1)$ and sells at the beginning of period t. $z_{t+1}^{f}$ is the percentage of firm $\mathrm{f}$ that the household buys at the beginning of period t. These percentages are measured as a number belonging to the closed interval $[0,1]$. Therefore, $z_{t}^{f} Q_{t}^{f}$ is the nominal value of the shares of firm $\mathrm{f}$ that the household sells at the beginning of period $t$. On the other hand, $z_{t+1}^{f} Q_{t}^{f}$ is the nominal amount that the household spends buying shares of firm $\mathrm{f}$ at the beginning of period $\mathrm{t}$. The shares of banks work in the same way: $Q_{t}^{\text {bank,l}}$ is the nominal price that the household would have to pay to buy $100 \%$ of bank 1 at the beginning of period t. $z_{t}^{b a n k, l}$ is the percentage of bank 1 that the household bought at the beginning of period ( $\mathrm{t}-1)$ and sells at the beginning of period t. $z_{t+1}^{b a n k, l}$ is the percentage of bank 1 that the household buys at the beginning of period $t$.

Let $C D_{t}$ denote the amount of checkable deposits that the household decides to hold at the beginning of period $t$.

Let us now write the portfolio allocation constraint and the cash-in-advance constraint that capture the structure of this model's consumer problem. At the beginning of period t, the household 
faces the following portfolio allocation constraint

$$
\begin{gathered}
\left(C D_{t-1}-P_{t-1} c_{t-1}\right)+W_{t-1} n_{t-1}^{s}+\sum_{f=1}^{f=F} z_{t}^{f} \Pi_{t-1}^{f}+\sum_{f=1}^{f=F} z_{t}^{f} Q_{t}^{f}+ \\
+\sum_{l=1}^{l=L} z_{t}^{\text {bank }, l} \Pi_{t-1}^{\text {bank,l}}+\sum_{l=1}^{l=L} z_{t}^{\text {bank }, l} Q_{t}^{\text {bank }, l}-B_{t}+\frac{B_{t+1}}{1+R_{t}}= \\
=\sum_{f=1}^{f=F} z_{t+1}^{f} Q_{t}^{f}+\sum_{l=1}^{l=L} z_{t+1}^{\text {bank }, l} Q_{t}^{\text {bank }, l}+C D_{t}
\end{gathered}
$$

The first term on the left-hand side of the equation, $\left(C D_{t-1}-P_{t-1} c_{t-1}\right)$, denotes checkable deposits not spent during the previous period. The second term denotes the household's wage earnings received at the end of period ( $t-1)$ [beginning of period $t$ ] in return for work effort supplied during period ( $t-1)$. These wage earnings are received in the form of checkable deposits (transferred from the firms' accounts into the household's account). The third term denotes the amount of dividends received from the $\mathrm{F}$ firms at the end of period ( $\mathrm{t}-1)$ corresponding to shares of firms bought by the household at the beginning of period $(\mathrm{t}-1)$. These dividends are received in the form of checkable deposits (transferred from the firms' accounts into the household's account). The fourth term corresponds to the amount that the household receives at the beginning of period $\mathrm{t}$ from selling the shares of firms she had bought at the beginning of period ( $\mathrm{t}-1)$. This amount is received in the form of checkable deposits. The fifth term denotes the amount of dividends received from the L banks at the end of period ( $t-1)$ corresponding to shares of banks bought by the household at the beginning of period $(\mathrm{t}-1)$. These dividends are received in the form of checkable deposits. The sixth term corresponds to the amount that the household receives at the beginning of period $t$ from selling the shares of banks she had bought at the beginning of period $(\mathrm{t}-1)$. This amount is received in the form of checkable deposits. The seventh term subtracts the amount that the household uses to pay the debt contracted from commercial banks at the beginning of period ( $\mathrm{t}-1)$. This payment is made by destroying part of the checkable deposits that the household owns in its current account. The eighth term adds the amount received from the new loan that the household obtains from the banks at the beginning of period $t$. This amount is received in the form of new checkable deposits created by the banks.

In short, the left-hand side of the equation gives the total amount of checkable deposits that the household owns at the beginning of period $t$. At the beginning of period $t$, the household uses the whole of this amount in the following way: she buys shares of firms and of banks and she keeps the rest as checkable deposits (the terms on the right-hand side of the equation). As a way of modelling the fact that shares are less liquid than deposits, we assume that the amount spent buying shares at the beginning of period $t$ cannot be used to buy consumption goods during period $t$ : shares bought at the beginning of period $t$ can only be sold at the end of period t. Hence, in deciding the amount that she will keep as checkable deposits, $C D_{t}$, the household must be aware that in 
order to buy consumption goods during period t, she can only use checkable deposits. This is what the cash-in-advance constraint (which follows) states in a very clear way. This cash-in-advance constraint is

$$
P_{t} c_{t}=C D_{t}
$$

Note that the cash-in-advance constraint is not written as an inequality because checkable deposits are dominated in terms of return by other assets (shares, in this case). This being so, it wouldn't be optimal for the household to hold an amount of checkable deposits greater than the amount she needs to buy consumption goods during the period.

Let us now show that the portfolio allocation constraint (equation 4) and the cash-in-advance constraint (equation 5) together imply a budget constraint similar to the budget constraints we can find in RBC models. Since the cash-in-advance constraint (equation 5) is always binding, it must have been binding in period $(t-1)$. Therefore, we have $P_{t-1} c_{t-1}=C D_{t-1}$. Using this equality and equation 5 in the portfolio allocation constraint (equation 4 ), and then rearranging the equation, we obtain

$$
\begin{gathered}
W_{t-1} n_{t-1}^{s}+\sum_{f=1}^{f=F} z_{t}^{f} \Pi_{t-1}^{f}+\sum_{f=1}^{f=F} z_{t}^{f} Q_{t}^{f}+\sum_{l=1}^{l=L} z_{t}^{\text {bank }, l} \Pi_{t-1}^{\text {bank }, l}+\sum_{l=1}^{l=L} z_{t}^{\text {bank }, l} Q_{t}^{\text {bank }, l}+\frac{B_{t+1}}{1+R_{t}}= \\
=B_{t}+P_{t} c_{t}+\sum_{f=1}^{f=F} z_{t+1}^{f} Q_{t}^{f}+\sum_{l=1}^{l=L} z_{t+1}^{\text {bank }, l} Q_{t}^{\text {bank }, l}
\end{gathered}
$$

This equation is the consumer's budget constraint. This equation simply states that the total amount of money the household obtains at the beginning of period $t$ [wage earnings, dividend earnings from firms, money received from selling the shares of firms bought at the beginning of period ( $t-1$ ), dividend earnings from banks, money received from selling the shares of banks bought at the beginning of period ( $\mathrm{t}-1$ ), and the amount she borrows from the banks at the beginning of period $t$ ] must be equal to the amount the household spends at the beginning or during period $\mathrm{t}$ [payment of the debt contracted from banks at the beginning of period ( $\mathrm{t}-1)$, consumption expenditure, purchase of shares of firms and purchase of shares of banks].

We can summarize by saying that the portfolio allocation constraint and the cash-in-advance constraint together imply the consumer's budget constraint.

Let us now normalize the household's budget constraint (the purpose of the normalization is to write the model in terms of variables that are constant in the steady-state). We can do that by dividing both sides of the constraint by $R E S_{t-1}$. After doing this, we rearrange the equation and then define the following new variables:

$$
\begin{aligned}
& \mu_{t}=\frac{R E S_{t}}{R E S_{t-1}}-1, p_{t}=\frac{P_{t}}{R E S_{t-1}}, w_{t}=\frac{W_{t}}{R E S_{t-1}}, q_{t}^{f}=\frac{Q_{t}^{f}}{R E S_{t-1}}, \\
& q_{t}^{\text {bank }, l}=\frac{Q_{t}^{\text {bank }, l}}{R E S_{t-1}}, b_{t+1}=\frac{B_{t+1}}{R E S_{t-1}}, \pi_{t}^{f}=\frac{\Pi_{t}^{f}}{R E S_{t-1}}, \pi_{t}^{\text {bank }, l}=\frac{\Pi_{t}^{\text {bank }, l}}{R E S_{t-1}}
\end{aligned}
$$

After all these steps, we arrive at 


$$
\begin{gathered}
\frac{w_{t-1}}{1+\mu_{t-1}} n_{t-1}^{s}+\sum_{f=1}^{f=F} z_{t}^{f} \frac{\pi_{t-1}^{f}}{1+\mu_{t-1}}+\sum_{f=1}^{f=F} z_{t}^{f} q_{t}^{f}+\sum_{l=1}^{l=L} z_{t}^{\text {bank,l}} \frac{\pi_{t-1}^{\text {bank }, l}}{1+\mu_{t-1}}+\sum_{l=1}^{l=L} z_{t}^{\text {bank }, l} q_{t}^{\text {bank }, l}+\frac{b_{t+1}}{1+R_{t}}= \\
=\frac{b_{t}}{1+\mu_{t-1}}+p_{t} c_{t}+\sum_{f=1}^{f=F} z_{t+1}^{f} q_{t}^{f}+\sum_{l=1}^{l=L} z_{t+1}^{\text {bank }, l} q_{t}^{\text {bank }, l} \\
\qquad \text { for } \mathrm{t}=0,1,2,3, \ldots
\end{gathered}
$$

We suggest using the following initial condition concerning the household's debt position at the beginning of period 0

$$
B_{0}=W_{-1} n_{-1}^{s}+\sum_{f=1}^{f=F} z_{0}^{f} \Pi_{-1}^{f}+\sum_{l=1}^{l=L} z_{0}^{b a n k, l} \Pi_{-1}^{b a n k, l}
$$

This initial condition simply states that the household begins period 0 with a debt which equals the sum of the wage earnings, dividend earnings from firms and dividend earnings from banks that she receives there because of the hours she worked during period $(-1)$ and because of the shares of firms and of banks she bought at the beginning of period $(-1)$. Note that period 0 is not the period where the household's life starts but rather the period where our analysis of the economy starts (the household has been living for some periods and we catch her in period 0 and try to model her behaviour). In the Appendix, we show that this initial condition is the initial condition which naturally arises when we think back to its initial moment a closed economy without government and where firms don't borrow. This initial condition can also be normalized by dividing both sides of the equation by $R E S_{-1}$ giving

$$
\frac{b_{0}}{1+\mu_{-1}}=\frac{w_{-1}}{1+\mu_{-1}} n_{-1}^{s}+\sum_{f=1}^{f=F} z_{0}^{f} \frac{\pi_{-1}^{f}}{1+\mu_{-1}}+\sum_{l=1}^{l=L} z_{0}^{b a n k, l} \frac{\pi_{-1}^{b a n k, l}}{1+\mu_{-1}}
$$

Consequently, at the beginning of period 0 the household is looking into the future and acts in a way that can be described as follows

$$
\begin{aligned}
& \underset{c_{t}, \ell_{t}, n_{t}^{s}, b_{t+1}, z_{t+1}^{f}, z_{t+1}^{\text {bank,l}}}{M a x} E_{0}\left[\sum_{t=0}^{t=\infty} \beta^{t} u\left(c_{t}, \ell_{t}\right)\right] \\
& \text { s.t. } \\
& \frac{w_{t-1}}{1+\mu_{t-1}} n_{t-1}^{s}+\sum_{f=1}^{f=F} z_{t}^{f} \frac{\pi_{t-1}^{f}}{1+\mu_{t-1}}+\sum_{f=1}^{f=F} z_{t}^{f} q_{t}^{f}+\sum_{l=1}^{l=L} z_{t}^{\text {bank,l }} \frac{\pi_{t-1}^{\text {bank,l}}}{1+\mu_{t-1}}+\sum_{l=1}^{l=L} z_{t}^{\text {bank }, l} q_{t}^{\text {bank }, l}+\frac{b_{t+1}}{1+R_{t}}= \\
& =\frac{b_{t}}{1+\mu_{t-1}}+p_{t} c_{t}+\sum_{f=1}^{f=F} z_{t+1}^{f} q_{t}^{f}+\sum_{l=1}^{l=L} z_{t+1}^{\text {bank }, l} q_{t}^{\text {bank }, l} \\
& n_{t}^{s}+\ell_{t}=1
\end{aligned}
$$




$$
\begin{gathered}
\text { for } \mathrm{t}=0,1,2,3, \ldots \\
\frac{b_{0}}{1+\mu_{-1}}=\frac{w_{-1}}{1+\mu_{-1}} n_{-1}^{s}+\sum_{f=1}^{f=F} z_{0}^{f} \frac{\pi_{-1}^{f}}{1+\mu_{-1}}+\sum_{l=1}^{l=L} z_{0}^{b a n k, l} \frac{\pi_{-1}^{\text {bank }, l}}{1+\mu_{-1}}
\end{gathered}
$$

There are also initial conditions on holdings of shares [ assuming market clearing in the shares market in period $(-1)$, these initial conditions will be $z_{0}^{f}=\frac{1}{H}$ and $z_{0}^{b a n k, l}=\frac{1}{H}$ ], a standard transversality condition on the pattern of borrowing and non-negativity constraints.

The best way to summarize the formal structure of the consumer's optimization problem presented in this section is to say that it adds a specific initial condition to a cash-in-advance format. As will be shown in section 7 , the initial condition we add is such that, in equilibrium, it makes the cash-in-advance structure become a credit-in-advance constraint in period 0: since it creates a situation where the household starts period 0 with zero net wealth, the initial condition makes the household's need to obtain "cash" in order to buy consumption goods become synonymous with a need to borrow from a bank. With Rational Expectations the credit-in-advance constraint is propagated to all future periods.

\section{The Market Clearing Conditions}

With $\mathrm{H}$ homogeneous households, F homogeneous firms and L homogeneous banks, the market clearing conditions for period 0 are as follows. In the goods market, the condition is

$$
H c_{0}+F i_{0}=F y_{0} \Leftrightarrow c_{0}+\frac{F}{H}\left[k_{1}-(1-\delta) k_{0}\right]=\frac{F}{H} A_{0} F\left(k_{0}, n_{0}^{d}\right)
$$

In the labour market, the condition is

$$
H n_{0}^{s}=F n_{0}^{d} \Leftrightarrow n_{0}^{s}=\frac{F}{H} n_{0}^{d}
$$

In the bank loans market, the condition is

$$
\begin{gathered}
H \frac{B_{1}}{1+R_{0}}=L * B_{0}^{s} \Leftrightarrow \\
\Leftrightarrow H \frac{\left(B_{1} / R E S_{-1}\right)}{1+R_{0}}=L * \frac{B_{0}^{s}}{R E S_{-1}}
\end{gathered}
$$

Defining a new variable $b_{t}^{s}=\frac{B_{t}^{s}}{R E S_{t-1}}$ this last equation can be rewritten as

$$
\frac{b_{1}}{1+R_{0}}=\frac{L}{H} * b_{0}^{s}
$$

The market clearing condition in the shares market is that each firm and each bank should be completely held by the households (the only owners of shares in this model). Since households 
are all alike, each holds an equal share of each firm and an equal share of each bank. Therefore, the market clearing conditions in the shares' market are

$$
H z_{1}^{f}=1 \Leftrightarrow z_{1}^{f}=\frac{1}{H}
$$

and

$$
H z_{1}^{\text {bank,l}}=1 \Leftrightarrow z_{1}^{\text {bank }, l}=\frac{1}{H}
$$

\section{The Competitive General Market Equilibrium assuming $\mathbf{H}$ homoge- neous households, F homogeneous firms and L homogeneous banks plus Rational Expectations}

To obtain the system that describes the competitive general market equilibrium, we put together in a system the typical household's first order conditions (that give, in an implicit way, the household's demand and supply functions), the typical firm's first order conditions (that give, in an implicit way, the firm's demand and supply functions), the typical bank's supply of credit equation and the market clearing conditions.

The next step in solving this model is to normalize the typical bank's supply of credit equation (equation 1 ) by dividing both sides of the equation by $R E S_{t-1}$. Then, we normalize the typical firm's first-order conditions by dividing both sides of the equations by $R E S_{t-1}$. We then assume Rational Expectations and use a Certainty Equivalence argument. After all these steps and if we also assume that the production function is homogeneous of degree one and define the following new variables

$$
\begin{aligned}
& \bar{k}_{t}=\frac{F}{H} k_{t}, \bar{n}_{t}^{d}=\frac{F}{H} n_{t}^{d}, \bar{\pi}_{t}^{f}=\frac{F}{H} \pi_{t}^{f}, \bar{q}_{t}^{f}=\frac{F}{H} q_{t}^{f}, \\
& \bar{\pi}_{t}^{\text {bank }, l}=\frac{L}{H} \pi_{t}^{\text {bank }, l}, \bar{q}_{t}^{\text {bank }, l}=\frac{L}{H} q_{t}^{\text {bank }, l}
\end{aligned}
$$

we can write the system describing the Competitive General Market Equilibrium assuming $\mathrm{H}$ homogeneous households, F homogeneous firms and L homogeneous banks plus Rational Expectations and Certainty Equivalence as

$$
u_{1}\left(c_{t}, 1-n_{t}^{s}\right)=\lambda_{t} p_{t}
$$

$$
u_{2}\left(c_{t}, 1-n_{t}^{s}\right)=\beta \frac{w_{t}}{1+\mu_{t}} E_{t}\left[\lambda_{t+1}\right]
$$




$$
\lambda_{t}=\beta E_{t}\left[\lambda_{t+1}\right] \frac{1+R_{t}}{1+\mu_{t}}
$$

$$
\lambda_{t} \bar{q}_{t}^{f}=\beta E_{t}\left[\lambda_{t+1}\right]\left(\frac{\bar{\pi}_{t}^{f}}{1+\mu_{t}}+E_{t}\left[\bar{q}_{t+1}^{f}\right]\right)
$$

$$
\lambda_{t} \bar{q}_{t}^{b a n k, l}=\beta E_{t}\left[\lambda_{t+1}\right]\left(\frac{\bar{\pi}_{t}^{b a n k, l}}{1+\mu_{t}}+E_{t}\left[\bar{q}_{t+1}^{b a n k, l}\right]\right)
$$

$$
\frac{b_{t+1}}{1+R_{t}}=p_{t} c_{t}
$$

$$
p_{t} A_{t} F_{2}\left(\bar{k}_{t}, \bar{n}_{t}^{d}\right)=w_{t}
$$

$$
\begin{gathered}
E_{t}\left[A_{t+1}\right] F_{1}\left(\bar{k}_{t+1}, E_{t}\left[\bar{n}_{t+1}^{d}\right]\right)+(1-\delta)=\left(1+E_{t}\left[R_{t+1}\right]\right) \frac{p_{t}}{E_{t}\left[p_{t+1}\right]} \frac{1}{\left(1+\mu_{t}\right)} \\
b_{t}^{s}=\frac{1}{r^{r e q}}\left(1+\mu_{t}\right)
\end{gathered}
$$

$$
c_{t}+\left[\bar{k}_{t+1}-(1-\delta) \bar{k}_{t}\right]=A_{t} F\left(\bar{k}_{t}, \bar{n}_{t}^{d}\right)
$$

$$
n_{t}^{s}=\bar{n}_{t}^{d}
$$

$$
\frac{b_{t+1}}{1+R_{t}}=\frac{L}{H} b_{t}^{s}
$$




$$
z_{t+1}^{f}=\frac{1}{H}
$$

$$
z_{t+1}^{b a n k, l}=\frac{1}{H}
$$

$$
\bar{\pi}_{t}^{f}=p_{t} A_{t} F\left(\bar{k}_{t}, \bar{n}_{t}^{d}\right)-w_{t} \bar{n}_{t}^{d}-p_{t}\left[\bar{k}_{t+1}-(1-\delta) \bar{k}_{t}\right]
$$

$$
\bar{\pi}_{t}^{b a n k, l}=\frac{L}{H} \frac{1}{r^{r e q}}\left(1+\mu_{t}\right) R_{t}
$$

$$
\text { for } t=0,1,2,3, \ldots
$$

Equations 14-19 have their origin in the typical household's first order conditions.

Equation 19 is the credit-in-advance constraint which results from combining the household's budget constraint with the initial condition and then using the market clearing conditions from the shares' market. Let us be more precise about this. We start by showing that if we add our specific initial condition to the household's period 0 budget constraint, in equilibrium we obtain a credit-in-advance condition for period 0 . In order to prove this, we start by writing the household's budget constraint (equation 6 ) for period $t=0$

$$
\begin{gathered}
W_{-1} n_{-1}^{s}+\sum_{f=1}^{f=F} z_{0}^{f} \Pi_{-1}^{f}+\sum_{f=1}^{f=F} z_{0}^{f} Q_{0}^{f}+\sum_{l=1}^{l=L} z_{0}^{\text {bank }, l} \Pi_{-1}^{\text {bank,l}}+\sum_{l=1}^{l=L} z_{0}^{\text {bank }, l} Q_{0}^{\text {bank }, l}+\frac{B_{1}}{1+R_{0}}= \\
=B_{0}+P_{0} c_{0}+\sum_{f=1}^{f=F} z_{1}^{f} Q_{0}^{f}+\sum_{l=1}^{l=L} z_{1}^{\text {bank }, l} Q_{0}^{\text {bank }, l}
\end{gathered}
$$

Using the initial condition before normalization (equation 7) in this last equation, we obtain

$$
\frac{B_{1}}{1+R_{0}}=P_{0} c_{0}+\sum_{f=1}^{f=F} Q_{0}^{f}\left(z_{1}^{f}-z_{0}^{f}\right)+\sum_{l=1}^{l=L} Q_{0}^{\text {bank }, l}\left(z_{1}^{b a n k, l}-z_{0}^{b a n k, l}\right)
$$

Using the market clearing conditions in the firms' shares market and in the banks' shares market in periods $(-1)$ and 0 (which are $z_{0}^{f}=\frac{1}{H}, z_{1}^{f}=\frac{1}{H}, z_{0}^{b a n k, l}=\frac{1}{H}$ and $z_{1}^{b a n k, l}=\frac{1}{H}$ ) this last equation becomes

$$
\frac{B_{1}}{1+R_{0}}=P_{0} c_{0}
$$


which means that, in equilibrium, the household will have to borrow at the beginning of period 0 an amount equal to the amount it wants to spend buying consumption goods during period 0 (i.e., in equilibrium, there is a credit-in-advance constraint for period 0). Dividing both sides of this equation by $R E S_{-1}$, we obtain equation 19 for period $t=0$. If we assume Rational Expectations, this credit-in-advance constraint is propagated to all future periods (periods $1,2,3, \ldots$ ). Let us show why this happens.

By assuming Rational Expectations we introduce all future budget constraints of the household and all future market clearing conditions into the structure of the mathematical representation of this economy. Hence, we can reason starting from period 0 and going successively into every future period in the following way. We first write the following tautology

$$
B_{1}=\frac{B_{1}}{1+R_{0}}\left(1+R_{0}\right) \Leftrightarrow B_{1}=\frac{B_{1}}{1+R_{0}}+\frac{B_{1}}{1+R_{0}} R_{0}
$$

This tautology simply says that the household's debt at the beginning of period 1 is equal to the principal borrowed at the beginning of period 0 plus interest on it.

Using the credit-in-advance constraint for period 0 which we have just derived (equation 30), this last equation can be written as

$$
B_{1}=P_{0} c_{0}+\frac{B_{1}}{1+R_{0}} R_{0}
$$

Using the market clearing condition in the goods market in period 0 (equation 8), we obtain

$$
B_{1}=\frac{F}{H}\left[P_{0} A_{0} F\left(k_{0}, n_{0}^{d}\right)-P_{0}\left[k_{1}-(1-\delta) k_{0}\right]\right]+\frac{B_{1}}{1+R_{0}} R_{0}
$$

Using the definition of profits of firm $\mathrm{f}$ (equation 3 ) in period 0 , this becomes

$$
\begin{aligned}
& B_{1}=\frac{F}{H}\left[\Pi_{0}^{f}+W_{0} n_{0}^{d}\right]+\frac{B_{1}}{1+R_{0}} R_{0} \Leftrightarrow \\
& \Leftrightarrow B_{1}=W_{0} \frac{F}{H} n_{0}^{d}+\frac{F}{H} \Pi_{0}^{f}+\frac{B_{1}}{1+R_{0}} R_{0}
\end{aligned}
$$

With the market clearing condition in the labour market (equation 9), we obtain

$$
B_{1}=W_{0} n_{0}^{s}+\frac{F}{H} \Pi_{0}^{f}+\frac{B_{1}}{1+R_{0}} R_{0}
$$

Using the market clearing condition from the bank loans market (equation 10), we obtain

$$
B_{1}=W_{0} n_{0}^{s}+\frac{F}{H} \Pi_{0}^{f}+\frac{L}{H} B_{0}^{s} R_{0}
$$

Using equation 1 , this last equation becomes

$$
B_{1}=W_{0} n_{0}^{s}+\frac{F}{H} \Pi_{0}^{f}+\frac{L}{H} \frac{1}{r^{r e q}} R E S_{0} R_{0}
$$

Using the definition of profits of bank 1 in period 0 (equation 2), we obtain 


$$
B_{1}=W_{0} n_{0}^{s}+\frac{F}{H} \Pi_{0}^{f}+\frac{L}{H} \Pi_{0}^{b a n k, l}
$$

Finally, using the market clearing conditions in the shares market, this can be written as

$$
B_{1}=W_{0} n_{0}^{s}+\sum_{f=1}^{f=F} z_{1}^{f} \Pi_{0}^{f}+\sum_{l=1}^{l=L} z_{1}^{\text {bank }, l} \Pi_{0}^{\text {bank }, l}
$$

Note that this equation is identical in form to the initial condition we propose using for period 0 (equation 7) but written one period ahead. In other words, it is an initial condition for period $t=1$. This is an interesting property of the initial condition we propose using: if we assume it holds at the beginning of period 0 , then the structure of the model will reproduce it automatically into the following periods. Combining equation 31 with the household's budget constraint for period $t=1$, we obtain

$$
\frac{B_{2}}{1+R_{1}}=P_{1} c_{1}
$$

which is a credit-in-advance constraint identical in form to the credit-in-advance constraint for period 0 which we have already obtained (equation 30) but written one period ahead. In other words, it is a credit-in-advance constraint for period 1. Dividing both sides of this equation by $R E S_{0}$, we obtain equation 19 for period $t=1$.

If we repeat the whole reasoning we will also obtain a credit-in-advance constraint for period $t=2$. And if we successively repeat the whole reasoning, we will obtain a credit-in-advance constraint for all future periods.

The intuition behind this propagation of the credit-in-advance constraint is as follows. The initial condition for the beginning of period 0 forces the household to borrow from the banks at the beginning of period 0 the amount she wants to spend buying consumption goods from the firms during period 0 . In equilibrium, the amount of consumption desired by the household is equal to output per household minus investment per household (this follows from the market clearing condition in the goods market). Using the definition of firm's profits and the market clearing conditions in the labour market and in the firm shares market, it is easy to show that output per household minus investment per household is equal to the sum of wage earnings and firm dividend earnings of each household. Hence, what the household wants to borrow at the beginning of period 0 , is an amount which is equal to the sum of her wage earnings and firm dividend earnings. Therefore, at the end of the period 0 (beginning of period 1) the household's debt will be this amount plus interest on it. However, since the interest paid to banks is equal to the dividends the banks will pay the household, the total debt of the household at the end of the period 0 (beginning of period 1) can be expressed as the sum of wage earnings and firm dividend earnings and bank dividend earnings of each household. But this household's debt at the beginning of period 1 is just what the initial condition had forced the household's debt to be at the beginning of period 0 . 
The previous paragraph can be summarized as follows. The initial condition forces households to borrow at the beginning of period 0 an amount which is equal to the value of consumption. Consumption is equal to output less investment. Output less investment is equal to wages plus firm dividends (this follows from the definition of firm profits). Hence, what the household wants to borrow at the beginning of period 0 is an amount which is equal to the value of wages plus firm dividends. This implies a debt at the end of period 0 equal to wages plus firm dividends plus interest on this amount. Since the interest paid to banks corresponds to bank dividends, we can conclude that the household's debt at the end of period 0 is equal to wages plus firm dividends plus bank dividends. But this household's debt at the end of period 0 (beginning of period 1) is just what the initial condition had forced the household's debt to be at the beginning of period 0 . Hence, the story is repeated in the following period and beyond that till the end of time.

Equations 20 and 21 have their origin in the typical firm's first order conditions. Equation 22 has its origin in the typical bank's supply of credit equation. Equations 23-27 are the market clearing conditions. Equation 28 results from multiplying the typical firm's normalized profit function by $(F / H)$. Equation 29 results from multiplying the typical bank's normalized profit function by $(L / H)$.

We have 2 exogenous variables $\left(A_{t}\right.$ and $\left.\mu_{t}\right)$ and 16 endogenous variables. The specific utility and production functions used were $u\left(c_{t}, \ell_{t}\right)=\ln c_{t}+\phi \ln \ell_{t}$ and $A_{t} F\left(k_{t}, n_{t}^{d}\right)=A_{t}\left(k_{t}\right)^{1-\alpha}\left(n_{t}^{d}\right)^{\alpha}$.

\section{Calibration}

In order to study the dynamic properties of the model, we first log-linearize each of the equations in the system 14-29 around the steady-state values of the variables. The log-linearized system was then calibrated. To calibrate the log-linearized system we used the following parameters. With the specific utility function we are using we obtain

\begin{tabular}{|l|c|}
\hline Elasticity of the MU of consumption with respect to consumption & -1 \\
\hline Elasticity of the MU of consumption with respect to leisure & 0 \\
\hline Elasticity of the MU of leisure with respect to consumption & 0 \\
\hline Elasticity of the MU of leisure with respect to leisure & -1 \\
\hline
\end{tabular}

where MU denotes "Marginal Utility". From the U.S. data, we obtain

\begin{tabular}{|l|l|l|}
\hline & value & source \\
\hline Investment share of total expenditure in the s.s. $(i / y)$ & 0.167 & Barro (1993) \\
\hline Labour's share $(\alpha)$ & 0.58 & King et al. (1988) \\
\hline Labour supply in the steady-state $\left(n^{s}\right)$ & 0.2 & King et al. (1988) \\
\hline Nominal interest rate in the steady-state $(R)$ & 0.016383 & FRED \\
\hline Rate of growth of the money supply in the s.s. $(\mu)$ & 0.009258 & Barro $(1993)$ \\
\hline
\end{tabular}

As usual we take the Postwar average as representing the steady-state value. The last two values in the table are per-quarter values. The nominal interest rate used was the Bank Prime 
Loan Rate. We have used data from the Federal Reserve Economic Data (FRED) to computed the average quarterly value of this rate for the period 1949-1986.

The value used to calibrate the steady-state rate of growth of the money supply (0.009258) was the average quarterly inflation rate for the period 1949-1986. The argument for using this value is as follows. Combining equations 19,22 and 25 above, which corresponds to equating the supply and the demand for money, we obtain

$$
\begin{gathered}
\frac{L}{H} \frac{1}{r^{r e q}}\left(1+\mu_{t}\right)=p_{t} c_{t} \Leftrightarrow \frac{L}{H} \frac{1}{r^{r e q}} \frac{R E S_{t}}{R E S_{t-1}}=\frac{P_{t}}{R E S_{t-1}} c_{t} \Leftrightarrow \\
\Leftrightarrow L * \frac{1}{r^{r e q}} * R E S_{t}=P_{t} * H * c_{t}
\end{gathered}
$$

Since $c_{t}$ is constant in the steady-state, this equation implies that in the steady-state the rate of growth of the money supply [the rate of growth of $\left(L * \frac{1}{r^{r e q}} * R E S_{t}\right)$ ] is equal to the rate of growth of $P_{t}$. In other words, since velocity is constant in the model (it is equal to one and this is because each unit of money is only used once during the period) and consumption is constant in the steady-state, we have a steady-state where the rate of growth of the money supply is equal to the rate of growth of the price level. We can therefore use the average inflation rate from the data to calibrate the steady-state rate of growth of the money supply in our model. The advantage of calibrating the steady-state rate of growth of the money supply in this way can be stated as follows. When we set a value for $\mu$ in this model, we are also setting a value for the model's steady-state inflation rate (as we have just seen). Hence, if we want to calibrate the steady-state nominal interest rate in this model using the average value of the nominal interest rate obtained from the U.S. data, the only way to obtain a value for the steady-state real interest rate in the model equal to the average value it takes in the U.S. data is to force the steady-state inflation rate in the model to be equal to the average value it takes in the data. This requires making the steady-state rate of growth of the money supply in the model $(\mu)$ equal the average inflation rate obtained from the data.

The values in the preceding table imply

\begin{tabular}{|l|l|}
\hline consumption share of output $(c / y)$ & 0.833 \\
\hline per-quarter rate of depreciation of the capital stock $(\delta)$ & 0.0047 \\
\hline household's discount factor $(\beta)$ & 0.993 \\
\hline
\end{tabular}

With this calibration, the model in this chapter has exactly the same steady-state values of physical output, consumption, investment, labour effort, real wage and real interest rate as would be obtained in a zero growth version of the RBC model presented in King, Plosser and Rebelo (1988) calibrated with our parameters. This means that we have built an economy with money which has exactly the same steady-state values of the key real variables that we would obtain in a benchmark economy without money. 


\section{The Dynamic Properties of the Model}

The response of the log-linearized model to shocks in the exogenous variables $\left(A_{t}\right.$ and $\left.\mu_{t}\right)$ can be obtained using the King, Plosser and Rebelo (1988) method. We first look at the impact of shocks in the firms' technological parameter. Afterwards, we look at the impact of shocks in the rate of growth of the money supply.

\subsection{The impact of technological shocks}

We next examine the results of two experiments which use shocks in the firms' technological parameter: impulse response experiment and stochastic simulation. In order to perform these two experiments, we assumed that the technological parameter evolves according to

$$
\hat{A}_{t}=0.9 \hat{A}_{t-1}+\varepsilon_{t}
$$

where $\hat{A}_{t}$ denotes the $\%$ deviation of $A_{t}$ from its steady-state value and $\varepsilon_{t}$ is a white noise.

\subsubsection{Impulse Response}

The first experiment we carried out was a standard impulse response experiment: a $1 \%$ shock in the typical firm's technological parameter. This exercise was performed assuming a constant rate of growth of the money supply (no monetary policy shocks). The results are plotted in figures 1 to 9. The first important thing to notice is that, in spite of the fact that ours is a monetary economy, it is capable of reproducing the key results that the King, Plosser and Rebelo (1988) paper is able to reproduce. First: consumption, investment and "hours of work" are procyclical. Second: consumption is less volatile than output and investment is more volatile than output. These are very well documented stylized facts about the United States economy [references on this include Kydland and Prescott (1990) and Backus and Kehoe (1992)].

We have checked the actual numbers and concluded that the impulse response results for the real variables $\hat{y}_{t}, \hat{c}_{t}, \hat{\imath}_{t}, \hat{n}_{t}^{s}$, the real wage and the capital stock are exactly the same as would be obtained in a zero growth version of the model presented in King, Plosser and Rebelo (1988) calibrated with our parameters.

As already mentioned, the model in this chapter has exactly the same steady-state values of physical output, consumption, investment, labour effort, real wage and real interest rate as the zero growth version of the model presented in King, Plosser and Rebelo (1988). This means that in this paper we have a model with money which not only has the same steady-state values of the key real variables as the zero growth version of the model without money presented in King, Plosser and Rebelo (1988) but also reacts in exactly the same way to an exogenous technological shock. 
Let us try to explain why the results obtained so far with our model (results obtained with a constant rate of growth of the money supply) seem to be the same as the results we would obtain with a zero growth version of the nonmonetary economy presented in King, Plosser and Rebelo (1988) calibrated with our parameters. We can summarize our description of the monetary flows among economic agents, done in the introduction to this article, as follows. At the beginning of each period, commercial banks tell the nonbank economic agents: "Take this money, use it for your transactions and, at the end of the period, give it back to us". We can say this because, although households actually have to pay interest on the amount that they borrow from the banks, they then receive the interest paid back in the form of bank dividends (this happens because banks are owned by the households and households are all alike). This means that the fact that households have to borrow to finance their expenditure does not involve an income effect. It seems that, with the specific utility function we are using and in the absence of monetary shocks, introducing money in the model in the way we did does not involve a substitution effect either. With the specific utility function we are using (log-linear utility function) and in the absence of monetary shocks, the ex-ante real interest rate is given by the same expression in the model of this paper and in the zero growth version of the model presented in King, Plosser and Rebelo. Also important to explain the fact that we obtain the same results with this model as we obtain with the zero growth version of the model presented in King, Plosser and Rebelo is the fact that in this model commercial banks provide money to the economy without spending resources (banks have no costs of operation).

The results in figures 1-9 were obtained with $\mu=0.009258$. It is important to point out that changes in the steady-state rate of growth of the money supply used in the calibration (changes in $\mu$ ) do not affect the impulse response results obtained with technological shocks as long as we adjust the steady-state nominal interest rate so as to make the steady-state real interest rate remain the same in our calibration (note that changing $\mu$ implies changing the steady-state rate of inflation). In other words, when money is supplied to the economy at a constant rate, the actual rate at which it is supplied has no influence on the results we obtain with technological shocks. The same is true in Cooley and Hansen's model.

\subsubsection{Stochastic Simulation}

The second experiment we carried out was a stochastic simulation exercise where only technological shocks were considered (the supply of money was assumed to grow at a constant rate). The results are shown in table 1 . These results are the same that are obtained in the same model without money [i.e., with a zero growth version of the model in King, Plosser and Rebelo (1988) calibrated with our parameters]. Cooley and Hansen (1989) also conclude that when only technological shocks are considered and the money supply grows at a constant rate, the statistics summarizing the behaviour of the real variables are the same as would be obtained in the same model without money [i.e., in the model of Hansen (1985)].

In our model, the correlation between "detrended prices" and "detrended output" is represented by the correlation between the "deviations of the normalized price of physical output from its 
steady-state" and the "deviations of physical output from its steady-state". As can be seen in table $1 \mathrm{~B}$, the value we obtained for this correlation in the stochastic simulation experiment was $-0.59$

In Cooley and Hansen's model, the correlation between the price level and real output that they obtained when there are only technological shocks and the rate of growth of the money supply is constant was -0.87 .

There are a number of relatively recent empirical studies concerning the relationship between prices and output. Since we have calibrated our model with measures computed using U.S. Postwar data, we shall concentrate only on empirical studies about the U.S. and only in that period.

Cooley and Hansen use quarterly data for the U.S. (the period considered is 1955:3-1984:1). All time series were seasonally adjusted, logged and detrended. The correlation of the "implicit GNP Deflator" with real GNP that they obtain is -0.53 . The correlation of the "Consumer Price Index" with real GNP that they obtain is -0.48 . Using deviations from trend and U.S. quarterly data for the period 1954-1989, Kydland and Prescott (1990) report a correlation coefficient of the cyclical deviations of the "implicit GNP Deflator" with the cyclical deviations of real GNP equal to -0.55. They also report a correlation coefficient of the cyclical deviations of the "Consumer Price Index" with the cyclical deviations of real GNP equal to -0.57. In the study by Cooley and Ohanian (1991), the simple contemporaneous correlation between detrended output and detrended prices is -0.67 for the period 1948:2-1987:2; it is -0.69 for the period 1954:1-1973:1 (a sample period beginning immediately after the Korean War and terminating before the first oil shock); and it is -0.87 for the period 1966:1-1987:2 (a period of high average inflation rate). Using Hodrick-Prescott filtered data the results are $-0.57,-0.36$ and -0.68 , respectively. Other studies that quote similar results include Backus and Kehoe (1992), Smith (1992), Chada and Prasad (1994) and King and Watson (1996).

These studies seem to indicate that the price level is countercyclical. This corresponds to the results from our impulse response experiment and stochastic simulation experiment. It is easy to understand why our model produces these simulation results. Combining equations 19, 22 and 25 above, which corresponds to equating the supply and the demand for money, we obtain

$$
p_{t} c_{t}=\frac{L}{H} \frac{1}{r^{l e g}}\left(1+\mu_{t}\right)
$$

Since we are not considering monetary shocks $\left(\mu_{t}=\mu\right)$, when $c_{t}$ moves upward (as a consequence of the positive technological shock), $p_{t}$ must move in the opposite direction.

\subsection{Monetary Policy}

We next examine the effect of a temporary increase in the rate of growth of the money supply on the behaviour of both nominal and real variables (in the model). In order to perform this experiment, we assumed that money shocks follow the following process

$$
\hat{\mu}_{t}=0.481 * \hat{\mu}_{t-1}+\frac{\xi_{t}}{0.01538}
$$


where $\hat{\mu}_{t}$ denotes the $\%$ deviation of $\mu_{t}$ from its steady-state value and $\xi_{t}$ is a white noise [this equation was obtained using the process estimated by Cooley and Hansen (1989)].

\subsubsection{Impulse Response}

Let us first look at the response of the model to a $1 \%$ shock in the rate of growth of the money supply (assuming that there are no technological shocks). The main results are plotted in figures 10 to 18 . The results in figures 10 to 13 show that a shock in the rate of growth of the money supply has an effect on the behaviour of real variables but that this effect is very small.

In spite of the fact that the impact is very small, the fact remains that the model does not give a purely nominal answer to a purely nominal shock. The reason why the increase in the rate of growth of the money supply triggers some (small) real effects is as follows.

Because (nominal) wages are only paid at the end of the period, the increase in the rate of growth of the money supply decreases the expected marginal benefit of devoting time to work (i.e., the right hand side of equation 15 increases). This makes sense because more inflation reduces the real value of the wage received at the end of the period. Hence, households reduce their supply of "hours of work" (figure 13).

This reduction in the supply of labour puts upward pressure on the real wage (figure 16).

Since $\bar{k}_{t}$ is pre-determined, we can see from equation 20 that the increase in the real wage will lead firms to reduce their labour demand. Because $\bar{k}_{t}$ is pre-determined, this decrease in the firms' labour demand implies an decrease in output (figure 10).

\subsubsection{Stochastic Simulation}

Let us now see what happens when we use an erratic money supply process to generate the rate of growth of the money supply in each period. Table 2 shows the stochastic simulation results obtained using the process given by 34 to generate the percentage deviations of $\mu_{t}$ from the steady-state $\mu_{t}$ of that same process (this stochastic simulation experiment combines technological shocks generated using equation 33 with monetary shocks generated using equation 34). Note that if $\xi_{t} \sim N\left(0, \sigma^{2}\right)$, then $\frac{\xi_{t}}{0.01538} \sim N\left(0,\left(\frac{\sigma}{0.01538}\right)^{2}\right)$. For $\sigma$ we used the value obtained by Cooley and Hansen (1989) in their estimation (0.0086). The average nominal interest rate used in the calibration $(R)$ was adjusted so that, given the new steady-state value used for $\mu$ (the steady-state value of process 34 ), the steady-state real interest rate would remain the same as the one we had in the previous stochastic simulation exercise.

We can see in table 2 that in terms of the real variables $\widehat{y}_{t}, \widehat{c}_{t}, \widehat{i}_{t}, \hat{n}_{t}^{s}, \hat{w}_{t}$ and $\widehat{p}_{t}$, the results (obtained with an erratic rate of growth of the money supply) are similar to the results we obtained in the stochastic simulation exercise reported in table 1 (where the rate of growth of the money supply was constant and we only had technological shocks). Hence, we can conclude that in our model money shocks have a very small impact on the behaviour of real variables. This again 
corresponds to what Cooley and Hansen have found using the same process that we used to generate the money shocks.

\section{Conclusion}

We have built a model of monetary creation and destruction which has exactly the same steadystate values of physical output, consumption, investment and "hours of work" as a zero growth version of the model presented in King, Plosser and Rebelo (1988).

The technological shock impulse response experiment performed using a constant rate of growth of the money supply gave us exactly the same results in terms of the real variables as would be obtained with the zero growth version of the King, Plosser and Rebelo model calibrated with our parameters.

The response of the model to temporary money shocks (temporary increases in the rate of growth of the money supply) can be summarized as follows: real variables are almost unaffected; inflation increases temporarily.

The contributions of this paper may be summarized as follows. First, we have developed a way of modelling the demand for bank credit by the households in a dynamic general equilibrium framework. Second, we have shown that in a setup where the source of all money to the economy is loans from banks to households the same results are obtained that are obtained with the model of Cooley and Hansen where money is supplied to the economy in a less realistic way. 


\section{APPENDIX}

In this Appendix we show that the initial condition on the household's problem that we used in the main text is the initial condition which naturally arises when we think back to its initial moment a closed economy without government and where firms don't borrow. We argue that when we start our analysis of the economy at a certain point in time which is in the middle of History (let us denote this point by period 0), the specific initial condition describing the household's debt position at the beginning of period 0 that we ought to use is the one we have used in this article.

Let us consider a closed economy where there are only households, firms and banks and where firms don't borrow. Let us imagine that we are at the moment in time where serious economic activity is going to begin and denote this "Beginning of the economy" period by $t_{B}$. Since production is only going to take place during period $t_{B}$, firms will only receive income from the sales of the final good during period $t_{B}$ and hence will only pay wages and dividends at the end of period $t_{B}$. However, in order to be able to buy consumption goods from the firms during period $t_{B}$ households must use money. The only possibility they have to obtain this money at the beginning of period $t_{B}$ is to obtain a loan from a bank. Hence, when the household is at the beginning of period $t_{B}$ and considering choices for $t_{B}$ and future periods she faces the following set of budget constraints. For period $t_{B}$ the budget constraint is

$$
\frac{B_{t_{B}+1}}{1+R_{t_{B}}}=P_{t_{B}} c_{t_{B}}+\sum_{f=1}^{f=F} Q_{t_{B}}^{f}\left(z_{t_{B}+1}^{f}-z_{t_{B}}^{f}\right)+\sum_{l=1}^{l=L} Q_{t_{B}}^{\text {bank,l}}\left(z_{t_{B}+1}^{\text {bank }, l}-z_{t_{B}}^{\text {bank,l}}\right)
$$

This budget constraint for period $t_{B}$ simply states that, at the beginning of period $t_{B}$, the household must borrow from the banks an amount enough to finance her consumption expenditure during period $t_{B}$ and to finance her net purchase of shares of firms and of shares of banks.

Since the household is looking into the future, when she is at the beginning of period $t_{B}$ she also takes into account the budget constraints for periods $\left(t_{B}+1\right),\left(t_{B}+2\right),\left(t_{B}+3\right), \ldots$ which are given by

$$
\begin{gathered}
W_{t_{B}-1+i} n_{t_{B}-1+i}^{s}+\sum_{f=1}^{f=F} z_{t_{B}+i}^{f} \Pi_{t_{B}-1+i}^{f}+\sum_{f=1}^{f=F} z_{t_{B}+i}^{f} Q_{t_{B}+i}^{f}+\sum_{l=1}^{l=L} z_{t_{B}+i}^{\text {bank,l}} \Pi_{t_{B}-1+i}^{\text {bank }, l}+\sum_{l=1}^{l=L} z_{t_{B}+i}^{\text {bank }, l} Q_{t_{B}+i}^{\text {bank }, l}+ \\
+\frac{B_{t_{B}+1+i}}{1+R_{t_{B}+i}}=B_{t_{B}+i}+P_{t_{B}+i} c_{t_{B}+i}+\sum_{f=1}^{f=F} z_{t_{B}+1+i}^{f} Q_{t_{B}+i}^{f}+\sum_{l=1}^{l=L} z_{t_{B}+1+i}^{\text {bank }, l} Q_{t_{B}+i}^{\text {bank }, l} \\
\text { for } \mathrm{i}=1,2,3, \ldots
\end{gathered}
$$

These budget constraints for periods $\left(t_{B}+1\right),\left(t_{B}+2\right),\left(t_{B}+3\right), \ldots$ are identical to the household's budget constraints examined in section 5 and can be explained in the same way.

Note that when the household is at the beginning of period $t_{B}$, the budget constraint for $t_{B}$ is different from the budget constraint for following periods (this happens because at $t_{B}$ there is no previous period). 
The important thing that follows from this structure is that, whatever the optimal decisions of economic agents are, in equilibrium there is an initial condition for period $\left(t_{B}+1\right)$ which can be computed. In other words, we can use the household's budget constraint in period $t_{B}$, the market clearing conditions for period $t_{B}$ and the definitions of profits of firms and of profits of banks to compute an initial condition for the optimization problem of the household in period $\left(t_{B}+1\right)$. In order to derive this initial condition, we start by taking the budget constraint for period $t_{B}$ [equation 35]. Imposing on that equation the market clearing conditions in the shares market in period $t_{B}$ [which are $z_{t_{B}+1}^{f}=\frac{1}{H}$ and $\left.z_{t_{B}+1}^{\text {bank,l}}=\frac{1}{H}\right]$ and assuming that the economy starts with every household owning the same share of each firm and each household owning the same share of each bank so that we also have $z_{t_{B}}^{f}=\frac{1}{H}$ and $z_{t_{B}}^{b a n k, l}=\frac{1}{H}$, we obtain

$$
\frac{B_{t_{B}+1}}{1+R_{t_{B}}}=P_{t_{B}} c_{t_{B}}
$$

We now write the following tautology

$$
B_{t_{B}+1}=\frac{B_{t_{B}+1}}{1+R_{t_{B}}}\left(1+R_{t_{B}}\right) \Leftrightarrow B_{t_{B}+1}=\frac{B_{t_{B}+1}}{1+R_{t_{B}}}+\frac{B_{t_{B}+1}}{1+R_{t_{B}}} R_{t_{B}}
$$

This tautology simply says that the household's debt at the beginning of period $\left(t_{B}+1\right)$ is equal to the principal borrowed at the beginning of period $t_{B}$ plus interest on it.

Using equation 37 , this is equivalent to writing

$$
B_{t_{B}+1}=P_{t_{B}} c_{t_{B}}+\frac{B_{t_{B}+1}}{1+R_{t_{B}}} R_{t_{B}}
$$

Using the market clearing condition in the goods market in period $t_{B}$ [equation 8 written with 0 replaced by $\left.t_{B}\right]$, we obtain

$$
B_{t_{B}+1}=\frac{F}{H}\left[P_{t_{B}} A_{t_{B}} F\left(k_{t_{B}}, n_{t_{B}}^{d}\right)-P_{t_{B}}\left[k_{t_{B}+1}-(1-\delta) k_{t_{B}}\right]\right]+\frac{B_{t_{B}+1}}{1+R_{t_{B}}} R_{t_{B}}
$$

Using the definition of nominal profits of firm $\mathrm{f}$ in period $t_{B}$ [see equation 3], we obtain

$$
B_{t_{B}+1}=\frac{F}{H}\left[\Pi_{t_{B}}^{f}+W_{t_{B}} n_{t_{B}}^{d}\right]+\frac{B_{t_{B}+1}}{1+R_{t_{B}}} R_{t_{B}} \Leftrightarrow B_{t_{B}+1}=W_{t_{B}} \frac{F}{H} n_{t_{B}}^{d}+\frac{F}{H} \Pi_{t_{B}}^{f}+\frac{B_{t_{B}+1}}{1+R_{t_{B}}} R_{t_{B}}
$$

With the market clearing condition in the labour market [equation 9 written with 0 replaced by $\left.t_{B}\right]$, this becomes

$$
B_{t_{B}+1}=W_{t_{B}} n_{t_{B}}^{s}+\frac{F}{H} \Pi_{t_{B}}^{f}+\frac{B_{t_{B}+1}}{1+R_{t_{B}}} R_{t_{B}}
$$

Using the market clearing condition from the bank loans market (see equation 10 and equation 1), we obtain

$$
B_{t_{B}+1}=W_{t_{B}} n_{t_{B}}^{s}+\frac{F}{H} \Pi_{t_{B}}^{f}+\frac{L}{H} \frac{1}{r^{l e g}} R E S_{t_{B}} R_{t_{B}}
$$

Using the definition of nominal profits of bank 1 in period $t_{B}$ [see equation 2], we obtain 


$$
B_{t_{B}+1}=W_{t_{B}} n_{t_{B}}^{s}+\frac{F}{H} \Pi_{t_{B}}^{f}+\frac{L}{H} \Pi_{t_{B}}^{b a n k, l}
$$

Finally, using the market clearing conditions in the shares market, this can be written as

$$
B_{t_{B}+1}=W_{t_{B}} n_{t_{B}}^{s}+\sum_{f=1}^{f=F} z_{t_{B}+1}^{f} \Pi_{t_{B}}^{f}+\sum_{l=1}^{l=L} z_{t_{B}+1}^{\text {bank }, l} \Pi_{t_{B}}^{\text {bank }, l}
$$

Remember that $B_{t_{B}+1}$ denotes the debt that the household has at the beginning of period $\left(t_{B}+1\right)\left[\frac{B_{t_{B}}+1}{1+R_{t_{B}}}\right.$ is the amount borrowed by the household at the beginning of period $t_{B}$ and $R_{t_{B}}$ is the interest rate between the beginning of period $t_{B}$ and the beginning of period $\left.\left(t_{B}+1\right)\right]$. Therefore, this last equation tells us that, in equilibrium, the amount the household borrows at the beginning of period $t_{B}$ is such that it implies a debt at the beginning of period $\left(t_{B}+1\right)$ equal to the sum of the wage earnings and dividend earnings that she will receive there [at the beginning of period $\left(t_{B}+1\right)$ which is the same as the end of period $\left.t_{B}\right]$. Hence, when we go on to consider the typical household's optimization problem at the beginning of period $\left(t_{B}+1\right)$ we should add this equation as an initial condition (describing the debt she carries from the previous period). Therefore, at the beginning of period $\left(t_{B}+1\right)$ the household faces the following constraints

$$
\begin{aligned}
& W_{t_{B}+i} n_{t_{B}+i}^{s}+\sum_{f=1}^{f=F} z_{t_{B}+1+i}^{f} \Pi_{t_{B}+i}^{f}+\sum_{f=1}^{f=F} z_{t_{B}+1+i}^{f} Q_{t_{B}+1+i}^{f}+\sum_{l=1}^{l=L} z_{t_{B}+1+i}^{\text {bank }, l} \Pi_{t_{B}+i}^{\text {bank }, l}+\sum_{l=1}^{l=L} z_{t_{B}+1+i}^{\text {bank }, l} Q_{t_{B}+1+i}^{\text {bank },}+ \\
& +\frac{B_{t_{B}+2+i}}{1+R_{t_{B}+1+i}}=B_{t_{B}+1+i}+P_{t_{B}+1+i} c_{t_{B}+1+i}+\sum_{f=1}^{f=F} z_{t_{B}+2+i}^{f} Q_{t_{B}+1+i}^{f}+\sum_{l=1}^{l=L} z_{t_{B}+2+i}^{\text {bank }, l} Q_{t_{B}+1+i}^{\text {bank }, l}
\end{aligned}
$$

for $\mathrm{i}=0,1,2,3, \ldots$

plus the initial condition

$$
B_{t_{B}+1}=W_{t_{B}} n_{t_{B}}^{s}+\sum_{f=1}^{f=F} z_{t_{B}+1}^{f} \Pi_{t_{B}}^{f}+\sum_{l=1}^{l=L} z_{t_{B}+1}^{b a n k, l} \Pi_{t_{B}}^{\text {bank }, l}
$$

Using the initial condition in the budget constraint written with $\mathrm{i}=0$, the budget constraint for $\mathrm{i}=0$ becomes

$$
\frac{B_{t_{B}+2}}{1+R_{t_{B}+1}}=P_{t_{B}+1} c_{t_{B}+1}+\sum_{f=1}^{f=F} Q_{t_{B}+1}^{f}\left(z_{t_{B}+2}^{f}-z_{t_{B}+1}^{f}\right)+\sum_{l=1}^{l=L} Q_{t_{B}+1}^{\text {bank }, l}\left(z_{t_{B}+2}^{\text {bank,l}}-z_{t_{B}+1}^{\text {bank,l}}\right)
$$

Therefore, the complete description of the budget constraints faced by the household at the beginning of period $\left(t_{B}+1\right)$ is






$$
\begin{gathered}
W_{t_{B}+i} n_{t_{B}+i}^{s}+\sum_{f=1}^{f=F} z_{t_{B}+1+i}^{f} \Pi_{t_{B}+i}^{f}+\sum_{f=1}^{f=F} z_{t_{B}+1+i}^{f} Q_{t_{B}+1+i}^{f}+\sum_{l=1}^{l=L} z_{t_{B}+1+i}^{\text {bank }, l} \Pi_{t_{B}+i}^{\text {bank,l}}+\sum_{l=1}^{l=L} z_{t_{B}+1+i}^{\text {bank }, l} Q_{t_{B}+1+i}^{\text {bank,l}+} \\
+\frac{B_{t_{B}+2+i}}{1+R_{t_{B}+1+i}}=B_{t_{B}+1+i}+P_{t_{B}+1+i} c_{t_{B}+1+i}+\sum_{f=1}^{f=F} z_{t_{B}+2+i}^{f} Q_{t_{B}+1+i}^{f}+\sum_{l=1}^{l=L} z_{t_{B}+2+i}^{\text {bank }, l} Q_{t_{B}+1+i}^{\text {bank,l}} \\
\text { for } \mathrm{i}=1,2,3, \ldots
\end{gathered}
$$

These two equations are identical in form to the two equations the household was facing at the beginning of period $t_{B}$ but written one period ahead. Therefore we can repeat the reasoning and derive an initial condition for the household's optimization problem at the beginning of period $\left(t_{B}+2\right)$. We will obviously obtain a condition which has the same form but written one period ahead: we obtain

$$
B_{t_{B}+2}=W_{t_{B}+1} n_{t_{B}+1}^{s}+\sum_{f=1}^{f=F} z_{t_{B}+2}^{f} \Pi_{t_{B}+1}^{f}+\sum_{l=1}^{l=L} z_{t_{B}+2}^{\text {bank }, l} \Pi_{t_{B}+1}^{\text {bank }, l}
$$

(and so on and so forth for all periods ahead). The conclusion to be drawn is that, when we start our analysis of the economy in the middle of History (period 0, for example), we should add to the household's optimization problem the following initial condition

$$
B_{0}=W_{-1} n_{-1}^{s}+\sum_{f=1}^{f=F} z_{0}^{f} \Pi_{-1}^{f}+\sum_{l=1}^{l=L} z_{0}^{b a n k, l} \Pi_{-1}^{b a n k, l}
$$

This is exactly the initial condition we have used in this paper. This initial condition was derived by thinking back to its initial moment an economy where firms don't borrow.

If instead we think back to its initial moment an economy where firms borrow the wages at the beginning of the period (in order to be able to pay wages in advance, at the beginning of the period, before production has taken place), the initial condition we obtain is $B_{0}=\sum_{f=1}^{f=F} z_{0}^{f} \Pi_{-1}^{f}+$ $\sum_{l=1}^{l=L} z_{0}^{b a n k, l} \Pi_{-1}^{b a n k, l}$. This initial condition simply states that the typical household starts period 0 with a debt which equals the profits she receives at the end of the previous period. This initial condition implies that the amount the household wants to borrow at the beginning of each period will be given by $\frac{B_{t+1}}{1+R_{t}}=P_{t} c_{t}-W_{t} n_{t}^{s}$. This makes sense because the fact that the household does not need to use her wage earnings to pay the debt from the previous period (as she does in the model we have presented in this article), means that she can use those wage earnings to buy consumption goods during the current period. Hence, the amount she will want to borrow equals the amount she wants to spend buying consumption goods minus the amount she already has (wage earnings). The results we obtained while working with this other initial condition were not very different. 


\section{References}

[1] Backus, D. K. and P. J. Kehoe. 1992. International evidence on the historical properties of business cycles. American Economic Review 82: 864-888.

[2] Barro, R. 1993. Macroeconomics, John Wiley \& Sons, Inc.

[3] Blanchard, O. and C. M. Khan. 1980. The solution to linear difference models under rational expectations. Econometrica 48: 1305-1311.

[4] Carlstrom, C. T. and T. S. Fuerst. 1996. Interest rate rules vs. money growth rules: a welfare comparison in a cash-in-advance economy. Journal of Monetary Economics 36: 247-267.

[5] Chadha, B. and Prasad, E. 1994. Are prices countercyclical? Evidence from the G-7. Journal of Monetary Economics 34: 239-57.

[6] Christiano, L. and M. Eichenbaum. 1995. Liquidity effects, monetary policy, and the business cycle. Journal of Money Credit and Banking 27: 1113-1136.

[7] Cooley, T. and G. Hansen.1989. The inflation tax in a Real Business Cycle model. American Economic Review 79: 733-748.

[8] Cooley, T. and L. Ohanian. 1991. The cyclical behaviour of prices. Journal of Monetary Economics 28: 25-60.

[9] Hansen, G. D. 1985. Indivisible Labor and the Business Cycle. Journal of Monetary Economics 16: $309-28$.

[10] Jefferson, P.N. 1997. On the neutrality of inside and outside money. Economica 64: 567-586.

[11] King, R.G., C.I. Plosser and S. Rebelo. 1988. Production, growth and business Cycles: I. The basic neoclassical model. Journal of Monetary Economics 21: 195-232.

[12] King, R. G. and Watson, M. W. 1996. Money, prices, interest rates and the business cycle. Review of Economics and Statistics 78: 35-53.

[13] Kydland, F. E. and E. C. Prescott. 1990. Business cycles: real facts and a monetary myth. Quarterly Review. Federal Reserve Bank of Minneapolis, Spring.

[14] Lucas, R. E., Jr. 1982. Interest rates and currency prices in a two-country world. Journal of Monetary Economics 10: 335-359.

[15] Lucas, R. E., Jr. and N. L. Stokey. 1987. Money and interest in a cash-in-advance economy. Econometrica 55: 491-514.

[16] Ravn, M. O. and Sola, M. 1995. Stylized facts and regime changes: are prices procyclical?. Journal of Monetary Economics 36: 497-526.

[17] Smith, R. T. 1992. The cyclical behaviour of prices. Journal of Money, Credit and Banking 24: $413-430$

[18] Woodford, M. 1994. Monetary policy and price level determinacy in a cash-in-advance economy. Economic Theory 4: 345-380. 
Table 1. Stochastic simulation. Shocks in the firms' technological parameter with a constant rate of growth of the money supply.

\section{A. Standard deviations (s.d.)}

\begin{tabular}{|l|l|l|}
\hline Variable & s.d. & s.d. of the variable divided by the s.d. of $\hat{y}_{t}$ \\
\hline$\hat{y}_{t}$ & 4.27 & 1.00 \\
\hline$\hat{c}_{t}$ & 1.96 & 0.46 \\
\hline$\hat{\imath}_{t}$ & 21.32 & 4.99 \\
\hline$\hat{n}_{t}^{s}$ & 2.80 & 0.65 \\
\hline$\hat{w}_{t}$ & 0.70 & 0.16 \\
\hline$\left(r_{t}-r\right)$ & 18.28 & 4.28 \\
\hline$\hat{p}_{t}$ & 1.96 & 0.46 \\
\hline
\end{tabular}

\section{B. Cross-correlations}

\begin{tabular}{|l|l|l|l|l|l|l|l|l|l|l|l|}
\hline Var. & \multicolumn{10}{|c|}{ Correlation with } \\
\hline & $\hat{y}_{t-12}$ & $\hat{y}_{t-8}$ & $\hat{y}_{t-4}$ & $\hat{y}_{t-2}$ & $\hat{y}_{t-1}$ & $\hat{y}_{t}$ & $\hat{y}_{t+1}$ & $\hat{y}_{t+2}$ & $\hat{y}_{t+4}$ & $\hat{y}_{t+8}$ & $\hat{y}_{t+12}$ \\
\hline$\hat{y}_{t}$ & 0.37 & 0.50 & 0.69 & 0.83 & 0.91 & 1.00 & 0.91 & 0.83 & 0.69 & 0.49 & 0.37 \\
\hline$\hat{c}_{t}$ & 0.65 & 0.65 & 0.63 & 0.62 & 0.60 & 0.59 & 0.55 & 0.52 & 0.46 & 0.37 & 0.31 \\
\hline$\hat{\imath}_{t}$ & 0.15 & 0.30 & 0.54 & 0.71 & 0.81 & 0.93 & 0.84 & 0.76 & 0.62 & 0.42 & 0.30 \\
\hline$\hat{n}_{t}^{s}$ & 0.09 & 0.24 & 0.49 & 0.67 & 0.77 & 0.89 & 0.80 & 0.72 & 0.59 & 0.40 & 0.28 \\
\hline$\hat{w}_{t}$ & 0.09 & 0.24 & 0.49 & 0.67 & 0.77 & 0.89 & 0.80 & 0.72 & 0.59 & 0.40 & 0.28 \\
\hline$r_{t}-r$ & -0.01 & -0.01 & 0.00 & 0.00 & 0.00 & -0.01 & 0.00 & -0.01 & 0.00 & 0.01 & 0.01 \\
\hline$\hat{p}_{t}$ & -0.65 & -0.65 & -0.63 & -0.62 & -0.60 & -0.59 & -0.55 & -0.52 & -0.46 & -0.37 & -0.31 \\
\hline
\end{tabular}


Table 2. Stochastic simulation. Shocks in the firms' technological parameter and shocks in the rate of growth of the money supply.

\section{A. Standard deviations (s.d.)}

\begin{tabular}{|l|l|l|}
\hline Variable & s.d. & s.d. of the variable divided by the s.d. of $\hat{y}_{t}$ \\
\hline$\hat{y}_{t}$ & 4.08 & 1.00 \\
\hline$\hat{c}_{t}$ & 1.60 & 0.39 \\
\hline$\hat{\imath}_{t}$ & 21.20 & 5.20 \\
\hline$\hat{n}_{t}^{s}$ & 2.79 & 0.68 \\
\hline$\hat{w}_{t}$ & 0.70 & 0.17 \\
\hline$\left(r_{t}-r\right)$ & 7.54 & 1.85 \\
\hline$\hat{p}_{t}$ & 1.60 & 0.39 \\
\hline
\end{tabular}

\section{B. Cross-correlations}

\begin{tabular}{|l|l|l|l|l|l|l|l|l|l|l|l|}
\hline Var. & \multicolumn{10}{|c|}{ Correlation with } \\
\hline & $\hat{y}_{t-12}$ & $\hat{y}_{t-8}$ & $\hat{y}_{t-4}$ & $\hat{y}_{t-2}$ & $\hat{y}_{t-1}$ & $\hat{y}_{t}$ & $\hat{y}_{t+1}$ & $\hat{y}_{t+2}$ & $\hat{y}_{t+4}$ & $\hat{y}_{t+8}$ & $\hat{y}_{t+12}$ \\
\hline$\hat{y}_{t}$ & 0.28 & 0.43 & 0.66 & 0.81 & 0.90 & 1.00 & 0.90 & 0.81 & 0.66 & 0.43 & 0.28 \\
\hline$\hat{c}_{t}$ & 0.61 & 0.61 & 0.60 & 0.57 & 0.56 & 0.54 & 0.49 & 0.45 & 0.37 & 0.26 & 0.19 \\
\hline$\hat{\imath}_{t}$ & 0.10 & 0.26 & 0.53 & 0.72 & 0.83 & 0.95 & 0.86 & 0.77 & 0.62 & 0.40 & 0.25 \\
\hline$\hat{n}_{t}^{s}$ & 0.05 & 0.22 & 0.50 & 0.69 & 0.80 & 0.92 & 0.83 & 0.75 & 0.60 & 0.38 & 0.24 \\
\hline$\hat{w}_{t}$ & 0.05 & 0.22 & 0.50 & 0.69 & 0.80 & 0.92 & 0.83 & 0.75 & 0.60 & 0.38 & 0.24 \\
\hline$r_{t}-r$ & -0.02 & -0.01 & 0.00 & 0.00 & 0.00 & -0.01 & -0.11 & -0.12 & -0.02 & 0.00 & 0.01 \\
\hline$\hat{p}_{t}$ & -0.61 & -0.61 & -0.60 & -0.57 & -0.56 & -0.54 & -0.49 & -0.45 & -0.37 & -0.26 & -0.19 \\
\hline
\end{tabular}




$$
11
$$




$$
11
$$




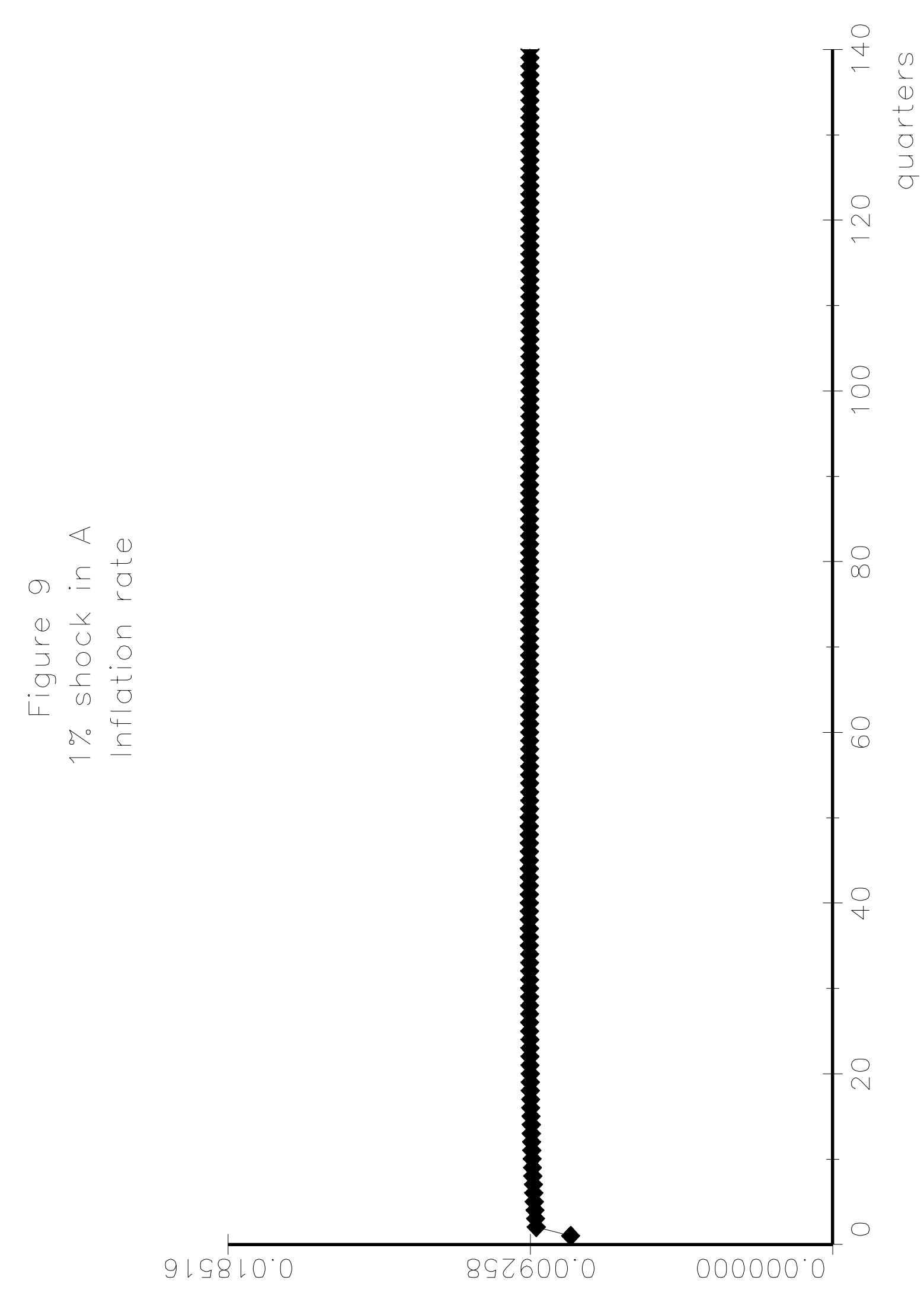




$$
11
$$




$$
11
$$




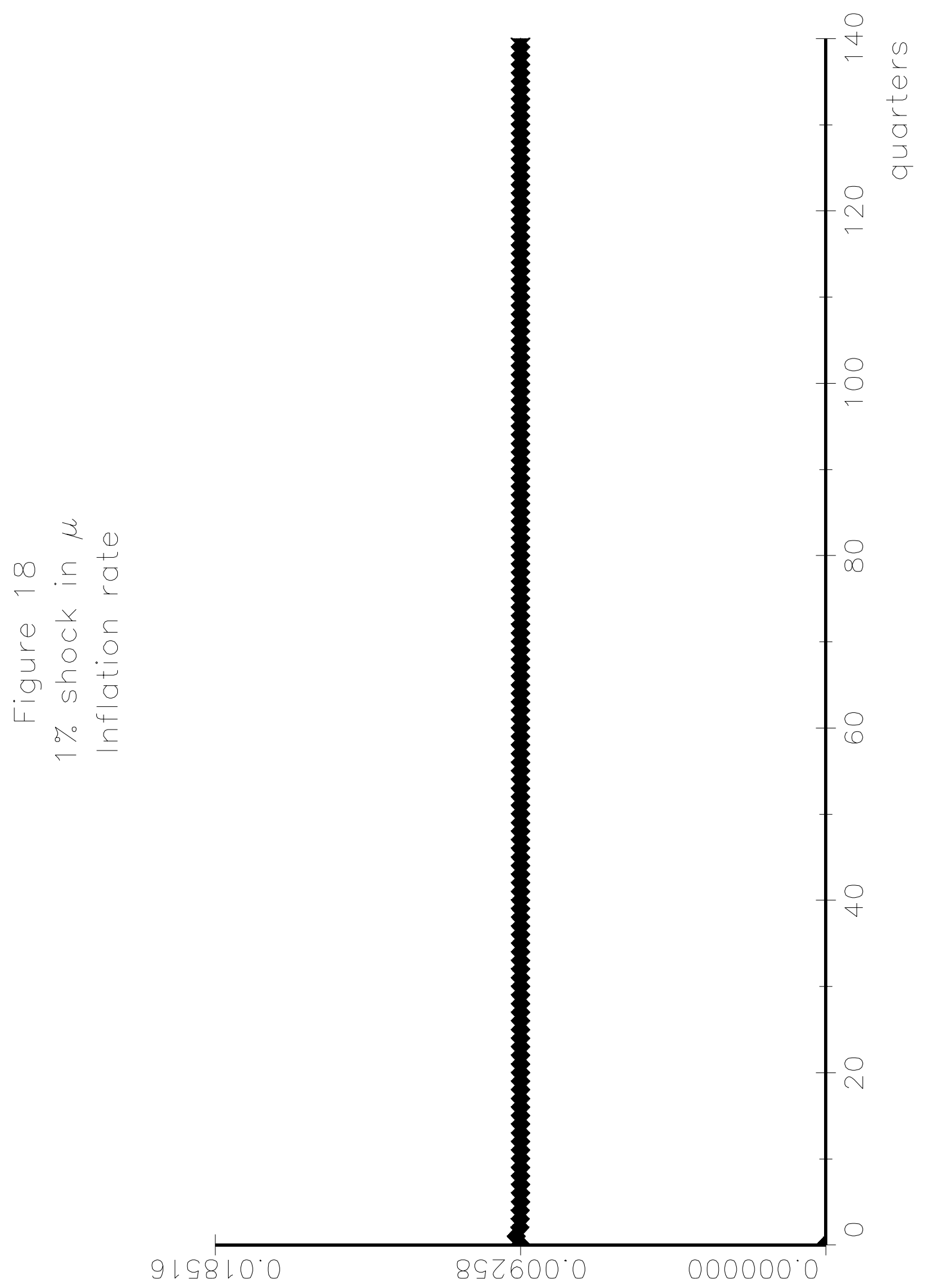

